\title{
Setting up a National Dialysis Service in India - Change, Choice and Principles
}

Vivekanand Jha

Executive Director, George Institute for Global Health India and Professor of Nephrology, University of Oxford.

\section{Address for correspondence:}

Vivekanand Jha, Executive Director, George Institute for Global Health India. 219-221 Splendor Forum, Jasola, New Delhi 110025. Email: vjha@pginephro.org 
With the announcement of a National Dialysis Service in the 2016 Budget speech by the Union Finance Minister, India is set to join the growing list of nations that provide free or highly subsidised treatment to patients with end-stage kidney failure.

Ever since the passage of the Medicare Act by US Congress, access to dialysis has become the benchmark for societal willingness to pay for medical care. According to the Ethical Considerations section of the Caring for Australasians with Renal Impairment (CARI) Guidelines": "Availability of resources should not be a reason to deny a patient access onto dialysis. Decisions to recommend or not to recommend dialysis should not be influenced by either availability of resources or potential litigation." The commitment to develop a National Dialysis Service indicates the willingness of India to meet with this benchmark.

Implementing the scheme needs attention to several aspects: who will be covered, what aspects of care of dialysis patients will fall within the ambit of coverage, what modes of dialysis - hemodialysis (HD) or peritoneal dialysis (PD) or both - will be included, addressing manpower needs, number and organization of facilities, payment model, quality control and assurance programs, and appropriate use of data generated by the program.

An affordable model is critical, considering payment for dialysis quickly adds up to a lot of money. About $2-6 \%$ of the health-care expenditure in developed nations is used to provide treatment for patients with end stage kidney disease (ESKD), even though they account for only $0 \cdot 1-0 \cdot 2 \%$ of the total population ${ }^{2}$. Dialysis costs accounted for $6 \cdot 3 \%$ of the Medicare budget in the USA, $4 \cdot 1 \%$ of the total health-care budget in Japan, and about $1 \cdot 3 \%$ of all health spending in the UK.

State funded programs typically cover all patients with ESKD who need dialysis, without distinction on the basis of socioeconomic status. This is because of the chronic nature of the treatment, which makes supporting long-term dialysis unviable for private insurance. In India, where state subsidy is usually limited to families with incomes below a certain threshold, it remains to be seen whether the National Service will cover only those or all subjects. 
Needs assessment requires knowledge of disease burden. There are no country level figures on the number of ESRD patients in India, but back of the envelope calculations on the basis of extrapolation of existing data ${ }^{3}$ suggest that provision will need to be made for about 206,900 patients in the first year. A total of 68,970 dialysis machines will be needed, assuming standard thrice weekly 4-hour dialysis sessions, 3 patients receiving dialysis on one machine daily, and units working 6 days a week. Over time, the number of patients on dialysis is likely to rise to 1.4 to 2.2 million $^{4}$.

In the speech, the Finance Minister has proposed the district as the unit of the service. India currently has 688 districts that vary tremendously in terms of population, rural-urban mix and geography. The 5 largest districts have populations in excess of 9 million each, whereas about 10 smallest have less than 50,000 people. The smallest district is less than $10 \mathrm{~km}^{2}$, whereas the largest is spread over $45,000 \mathrm{~km}^{2}$, with many people living in remote locations.

Setting up small hemodialysis units may be impractical for geographically large districts with relatively small populations, especially in remote locations. Small units are likely to have high setup costs, will need more staff, and have questionable long-term viability.

The National Service should be a hybrid program, with a pragmatic mix of both forms of dialysis. PD would be the best way to start, since it does not require major infrastructure set up. At the same time, HD units that allow efficiency and economies of scale should be developed in larger towns. Travel time is an important consideration, and patients who might need to travel long distances should be offered PD.

The high cost is related to the recurring cost of consumables, manpower salaries and expenses on management of complications. Local manufacturing of disposables should be prioritized. The high cost of PD fluid bags is inexplicable. There is no reason why these cannot be produced at a fraction of the current costs. Currently, it is common practice to reuse dialysis filters to cut costs 5 . Local manufacturing may allow phasing out of this practice.

Development of a service needs to make provision for potentially disruptive changes in the near future. A winner was announced recently for the Affordable Dialysis Prize ${ }^{6}$. The 
proposed solution might obviate the need for large infrastructure costs. It would be prudent to engage with organizations involved in supporting development of this technology so that the government is prepared to harness the best and cheapest technology.

Renal replacement therapy should be an integrated service, with patients moving from one treatment modality to the other on the basis of need and availability. Considering the Indian ESKD failure population is a couple of decades younger than that in Western countries, it is important to promote the transplant program, particularly improving donation from deceased donors. Lessons from states with successful programs should be implemented across the country ${ }^{7}$. Considering how transformative a successful transplant is for the patient, and the saving to the healthcare system, financial support should be available for transplant surgery and immunosuppressive therapy. It would be a shame if patients refused transplant because they can't afford it, whereas dialysis is available free.

Mounting evidence suggests that many elderly and frail patients do not have a survival benefit on dialysis, and experience a reduction in quality of life. Such people should have the option to not choose, or withdraw from dialysis. They must, however, continue to receive care for symptom relief and psychological support. The dialysis service should be coupled with a program of supportive care to meet with these needs ${ }^{8}$.

Availability of trained manpower will impact implementation. Currently India has about 1600 nephrologists, or about 1.2 for every million people $(\mathrm{pmp})^{9}$, and training programs are adding about 100 new nephrologists annually. At this rate, it will take 15-25 years to reach figures comparable to those in developed countries (8-30 pmp). Equally important is to address the current shortage of dialysis technicians and nurses.

The National Dialysis service has been proposed on the basis of a public-private partnership (PPP) model. Details on how the service providers will be paid are not known - whether it will be based on meeting process requirements, or will outcome parameters also be taken into consideration? A couple of states that run such schemes use the former model. As a result, while the coverage has increased, quality remains uncertain, and the survival is suboptimal. The optimal payment model should be based on a combination of process and 
outcome measures. Clarity will also be needed on "bundling" for other payments - in particular for anemia and CKD-MBD management.

Since dialysis will be a limited resource, at least in the initial stages, it is important that appropriate criteria are developed to select patients and any rationing is applied in a transparent manner.

The program should be coupled with a Dialysis Registry to track disease burden, healthcare expenditure, monitor quality, outcomes and resource utilization and allow comparisons. The Registry should be managed by independent academic organizations to avoid conflict of interest with service providers. Harnessing platforms that are being used for ongoing studies ${ }^{10}$ to evaluate outcomes of dialysis patients can help meet this objective.

The experience of other countries should inform the proposed service. Concerned with relatively static quality and mounting costs, the Australian nephrologists developed a "Call for Action", in 2011 that laid out steps to improve their PD program, and reduce the rates of complications $^{11}$. The resultant action has led to improvement in outcomes ${ }^{12}$. All this has been possible on the basis of the high quality data generated by the Australia and New Zealand Dialysis Registry (ANZDATA).

Given how expensive dialysis is, the National Dialysis Program should be coupled with a community-level program to identify and treat earlier stages of kidney disease through public-awareness campaigns, patient education, funding for research into chronic kidney disease, delivery of integrated care to manage kidney disease along with diabetes, hypertension and cardiovascular disease through family doctors and other health professionals, and reorientation of primary health care towards surveillance and intervention. These strategies have been successful in reducing ESKD incidence in several countries ${ }^{2}$.

The issues raised above require academic discussion. One hopes that the National Service framework is a partnership with all stakeholders: policymakers, nephrologists, nurses, technicians, service providers and patients. Standards will need to be developed for setting 
up dialysis units and assessment of quality parameters. The guidelines proposed by the Indian Society of Nephrology for setting up HD units ${ }^{13}$ should be used as a starting point.

Finally, new dialysis programs offer the opportunity to innovate - for example, the young and motivated patients could be offered the opportunity of getting strict alternate day nocturnal dialysis. ANZDATA Registry show better 5-year survival in patients treated with this regime compared to those on conventional thrice a week dialysis ${ }^{14}$. Finally, dialysis service might stimulate discussion around difficult task of undertaking randomised controlled trials in this area, especially using patient centered outcomes.

In conclusion, the National Dialysis Service is an exciting announcement, but places challenges before the healthcare community - none that cannot be overcome with thoughtful planning.

\section{References:}

1 Kainer G, Fetherstonhaugh D. Ethical considerations. Nephrology. 2010; 15.

2 Jha V, Garcia-Garcia G, Iseki K, Li Z, Naicker S, Plattner B, et al. Chronic kidney disease: global dimension and perspectives. Lancet. 2013; 382: 260-72.

3 Modi GK, Jha V. The incidence of end-stage renal disease in India: a population-based study. Kidney international. 2006; 70: 2131-3.

4 Liyanage T, Ninomiya T, Jha V, Neal B, Patrice HM, Okpechi I, et al. Worldwide access to treatment for end-stage kidney disease: a systematic review. Lancet. 2015; 385: 1975-82.

5 Jha V, Chugh KS. Dialysis in developing countries: Priorities and obstacles. Nephrology. 1996; 2: 65-71.

$6 \quad$ Knight J, Perkovic V. The Affordable Dialysis Prize steams ahead. Lancet. 2016; 387: 1040.

7 Reddy YN, Abraham G, Pavanathan A, Roy-Chaudhury P. Current state of renal transplantation in India. Journal of the Indian Medical Association. 2013; 111: 518-20, 22-3.

8 Davison SN, Levin A, Moss AH, Jha V, Brown EA, Brennan F, et al. Executive summary of the KDIGO Controversies Conference on Supportive Care in Chronic Kidney Disease: developing a roadmap to improving quality care. Kidney international. 2015; 88: 447-59.

9 Jha V. Current status of end-stage renal disease care in South Asia. Ethnicity \& disease. 2009; 19: S1-27-32. 
10 Jha V, John O, Joshi R, Kotwal S, Essue B, Jan S, et al. Dialysis outcomes in India: a pilot study. Nephrology. 2015; 20: 329-34.

11 Jose MD, Johnson DW, Mudge DW, Tranaeus A, Voss D, Walker R, et al. Peritoneal dialysis practice in Australia and New Zealand: a call to action. Nephrology. 2011; 16: 19-29.

12 Mudge DW, Boudville N, Brown F, Clayton P, Duddington M, Holt S, et al. Peritoneal dialysis practice in Australia and New Zealand: A call to sustain the action. Nephrology. 2016.

13 Indian Society of Nephrology Working group: Guidelines for setting up hemodialysis in India. Indian J Nephrol 2012; 22: Suppl S1-76.

14. Kerr PG, Polkinghorne KR, McDonald SP. Home hemodialysis in Australia: current perspective. Hemodial Int 2008; 12 Suppl 1: S6-S10. 